\title{
Cigarette, cigar and pipe smoking, passive smoke exposure, and risk of pancreatic cancer: a population-based study in the San Francisco Bay Area
}

Gregory J Tranah" ${ }^{*}$, Elizabeth A Holly², Furong Wang ${ }^{2}$ and Paige M Bracci ${ }^{2}$

\begin{abstract}
Background: To examine the influence of cigarette, cigar and pipe smoking, cessation of cigarette smoking and passive smoke exposure on the risk of pancreatic cancer.

Methods: Exposure data were collected during in-person interviews in a population-based case-control study of pancreatic cancer ( $N=532$ cases, $N=1701$ controls) in the San Francisco Bay Area. Odds ratios (ORs) were adjusted for potential confounders.

Results: The adjusted odds ratio (OR) of pancreatic cancer among current smokers was 1.9 (95\% confidence interval (CI), 1.4-2.7). A significant, positive trend in risk with increasing pack-years of smoking was observed (P-trend $<0.0001$ ). Compared with participants who continued to smoke, former smokers had no statistically significant elevation in risk of pancreatic cancer 10 years after smoking cessation, with risk reduced to that of never smokers regardless of prior smoking intensity. Both men and women experienced similar increased risk of pancreatic cancer with increasing smoking duration. Cigar and pipe smoking and exposure to passive smoke were not associated with pancreatic cancer.

Conclusions: Cigarette smoking is associated with an increased risk of pancreatic cancer. Smokers who had quit for $\geq 10$ years no longer experienced an increased risk. Future work will help to determine the effect of declining smoking rates on pancreatic cancer incidence.
\end{abstract}

\section{Background}

Pancreatic cancer is the fourth leading cause of death from cancer among men and women in the United States and is expected to result in 43,140 new cases and 36,800 deaths in 2010 [1]. Due to its aggressiveness and a lack of early detection methods, pancreatic cancer is often metastatic in patients at the time of diagnosis resulting in a 5-year relative survival rate for all stages of $<5 \%$. The incidence of pancreatic cancer varies by age, sex, and race - and survival differences by race have been observed [2-6].

Of the several modest risk factors that have been identified for pancreatic cancer, including obesity, diabetes,

\footnotetext{
* Correspondence: gtranah@psg.ucsf.edu

${ }^{1}$ California Pacific Medical Center Research Institute, CA, 94107, USA

Full list of author information is available at the end of the article
}

physical inactivity, chronic pancreatitis and dietary factors [7-12], cigarette smoking has been reported most consistently [2,13-17]. In a large meta-analysis [14] current cigarette smoking was associated with an overall relative risk (RR) of pancreatic cancer of 1.7 whereas current cigar and pipe smoking was associated with an approximate RR of 1.5. There was evidence of a doseresponse relationship between smoking and pancreatic cancer [14] although the risk for those who had quit for 10 or more years was not different from that of nonsmokers [14]. A recent pooled analysis from the Pancreatic Cancer Cohort Consortium [17] identified an odds ratio (OR) of 1.8 for current cigarette smoking and that risk was similar to that for never smokers after more than 15 years of smoking cessation.
C Biomed Central

๑ 2011 Tranah et al; licensee BioMed Central Ltd. This is an Open Access article distributed under the terms of the Creative Commons Attribution License (http://creativecommons.org/licenses/by/2.0), which permits unrestricted use, distribution, and reproduction in any medium, provided the original work is properly cited. 
It has been estimated that $25-30 \%$ of pancreatic cancer cases in the United States are related to cigarette smoking $[18,19]$. Because of their public health implications, the effects of smoking cessation on pancreas cancer risk are important to understand. In the present populationbased, case-control study of pancreatic cancer we examined cigarette, cigar and pipe smoking as risk factors for pancreas cancer. We quantified the relationship between cigarette smoking and pancreatic cancer and estimated the effects of smoking duration, pack-years smoked, cigarettes smoked/day and cigarette smoking cessation on risk of developing pancreatic cancer. Lastly, we assessed the effects of passive cigarette smoke exposure on the risk of pancreatic cancer.

\section{Methods}

\section{Study Participants}

Detailed methods for this case-control study have been published [20-24]. Briefly, a population-based case-control study of pancreatic cancer was conducted in six San Francisco Bay Area counties (Alameda, Contra Costa, Marin, San Francisco, San Mateo, and Santa Clara). Cases with primary adenocarcinoma of the exocrine pancreas were identified using rapid case ascertainment by the Northern California Cancer Center (Union City, CA) with a goal to identify patients in the study area within one month of diagnosis. Eligible cases were newly diagnosed between 1995 and 1999 with adenocarcinoma of the exocrine pancreas who were between 21 and 85 years old, resided in one of the six Bay Area counties listed above, were alive at the time of the first attempted contact, and could complete an interview in English. There were 65 out-of-area pancreatic cancer patients identified through clinical records at the UCSF Medical Center who were eligible to participate because they met all study criteria other than their place of residence at the time of diagnosis. Diagnoses for out-of-area patient participants were confirmed using patients' pathology reports and medical records. A total of 532 eligible cases completed the interview for a $67 \%$ response rate. The refusal rate was $8 \%$ among cases. No eligible patients with completed interviews were excluded from this analysis. Patient diagnoses were confirmed by participants' physicians and by the Surveillance, Epidemiology, and End Results abstracts that included histologic confirmation of disease.

Control participants for the in-area cases were identified within the six San Francisco Bay Area counties using random-digit dial (RDD), and were frequencymatched to cases by sex and 5-year age group in an approximate 3:1 ratio. Eligibility criteria were identical for case and control participants except for pancreatic cancer status. Control identification for those $>65$ years of age was supplemented by random selection from
Health Care Finance Administration lists (now the Centers for Medicare and Medicaid Services) for the six Bay Area counties. Out-of-area controls also were identified by RDD, were frequency matched to out-of-area cases by residential telephone area code and prefix, and by sex and 5-year age group. A total of 1,701 eligible control participants completed the study interview for a $67 \%$ response rate [21]. The refusal rate among controls was $9 \%$.

\section{Interviews}

Detailed in-person interviews were conducted in the homes of the participants or at a location of their choice for Bay Area participants and by telephone interview for out-of-area participants. No proxy interviews were conducted. The University of California San Francisco Committee on Human Research approved the study protocols and procedures. Written informed consent was obtained from each study participant before interview. Primary topics included on the questionnaire were: demographic factors, detailed job and occupational history, use of tobacco products and alcohol consumption, medical history including allergies, diabetes, pancreatitis and gallbladder disease, family medical history, anthropometric data and a detailed assessment of diet including average consumption of specific foods, vitamin supplement use and dietary modifications.

Race/ethnicity was based on self-report and was broadly defined as Caucasian, black/African-American, Asian, and Hispanic (black or white). Nine cases and 33 controls who were of mixed race/ethnicity were classified as "other race/ethnicity" for these analyses. Participants were defined as smokers if they had smoked $>100$ cigarettes in their lifetime. Former smokers were defined as those who had ceased smoking one year or more prior to diagnosis or interview. Those who had quit less than one year prior to diagnosis/interview were considered current smokers. Participants were considered cigar and/or pipe smokers if they had ever smoked pipes and/or cigars for $>6$ months. Body mass index (BMI; weight in kilograms divided by height in meters squared) was based on self-reported height and usual adult weight and was categorized based on quartiles of the distribution among controls by sex as follows: men: $<23.1 ; 23.1-<25.1$; $25.1-<27.1 ;>27.1 \mathrm{~kg} / \mathrm{m}^{2}$; and women: $<21.5 ; 21.5-<23.4$; $23.4-<25.8 ;>25.8 \mathrm{~kg} / \mathrm{m}^{2}$. Participants were defined as consumers of alcohol if they had ever had at least one alcoholic drink per month.

\section{Statistical analysis}

Unconditional logistic regression was used to obtain odds ratios (ORs) as estimates of relative risks (hereafter called risk) and 95\% confidence intervals (CIs). All models were adjusted for age in 5-year groups, sex, 
education level ( $\leq 12$ years, $12-16$ years, $>16$ years), race/ ethnicity (Hispanic white, non-Hispanic white, black or African-American, Asian, other), diabetes diagnosis, pancreatitis diagnosis, gallbladder disease (gallstones or gallbladder inflammation), alcohol intake and BMI [24-28]. Models for cigar/pipe smoking and passive smoke exposure were further adjusted for cigarette smoking status (never, past and current). In the combined analysis of smoking intensity and years of smoking cessation, similarity of ORs was tested using the Breslow-Day test for homogeneity.

\section{Results}

A total of 532 cases and 1,701 control participants completed the interview. There were 16 cases and 73 controls who reported smoking cigars or pipes but not cigarettes leaving a total of 516 cases and 1628 controls who were included in the final analyses of cigarette smoking. Distribution by age, education level, race, ethnicity, sex, BMI, diabetes diagnosis, pancreatitis diagnosis, gallbladder problems and alcohol intake for total pancreas cancer cases and controls are presented in Table 1. The mean age for pancreas cancer cases and control participants was 65 and 64 years, respectively. In general, cases were somewhat less educated and a greater proportion were men, black, had a high BMI (men only) and were more likely to have been diagnosed with diabetes, pancreatitis or gallbladder disease.

\section{Smoking Status and Quantity}

The OR for current smokers was 1.9 compared with never smokers (Table 2). Risk increased with increasing intensity of smoking that was assessed in three ways, as the number of cigarettes smoked per day, years smoked, and pack-years smoked (Table 2). Compared with nonsmokers, participants who smoked for at least 40 years had an OR of 1.8 and those who smoked at least 40 pack-years had an OR of 2.0. Analyses by sex and restricted race/ethnicity showed that men $(\mathrm{p}=0.004)$ and women $(\mathrm{p}=0.009)$ from all races/ethnicities, and that non-Hispanic whites $(\mathrm{p}=0.0002)$ experienced increased risk with increasing duration smoked (data not shown). Smoking 40 or more years was associated with similar increases in risk for men $(\mathrm{OR}=1.8,95 \% \mathrm{CI}$ $=1.2-2.9)$, women $(\mathrm{OR}=1.8,95 \% \mathrm{CI}=1.2-2.7)$ and non-Hispanic white men and women $(\mathrm{OR}=1.8,95 \% \mathrm{CI}$ $=1.3-2.6)$ (data not shown). Sample sizes were too small to examine associations with cigarette smoking among other race and ethnicity groups. Smoking at least one cigar or pipe per month for over six months was not associated with pancreatic cancer (Table 2).
Table 1 Characteristics of pancreatic cancer (PanCA) cases and controls in a population based study in the San Francisco Bay Area

\begin{tabular}{llll}
\hline Characteristic & & $\begin{array}{l}\text { PanCA } \\
\mathbf{N}=\mathbf{5 3 2}\end{array}$ & $\begin{array}{l}\text { Controls } \\
\mathbf{N}=\mathbf{1 7 0 1}\end{array}$ \\
\hline Age (years) & Mean (s.d.) & $65(11)$ & $64(11)$ \\
Education (years) & & $\mathrm{n}(\%)$ & $\mathrm{n}(\%)$ \\
& $1-12$ & $235(44)$ & $534(31)$ \\
& $12-16$ & $200(38)$ & $754(44)$ \\
Race/ethnicity & Over 16 & $97(18)$ & $413(24)$ \\
& & & \\
& White, non-Hispanic & $417(78)$ & $1357(80)$ \\
& White, Hispanic & $25(5)$ & $114(7)$ \\
& Black & $46(9)$ & $78(5)$ \\
Sex & Asian & $35(7)$ & $119(7)$ \\
& Other & $9(2)$ & $33(2)$ \\
& & & \\
& Men & $291(55)$ & $883(52)$ \\
& Women & $241(45)$ & $818(48)$
\end{tabular}

Usual adult BMI

Men

$<23.1$
$23.1-<25.1$
$25.1-<27.1$
$27.1+$

48 (17)

$222(25)$

(n)

(1)

\section{Women}

$<21.5$
$21.5-<23.4$
$23.4-<25.8$
$25.8+$

$67(28)$

$51(21)$

Diabetes diagnosis

$\begin{array}{lll}\text { Yes } & 69(13) & 152(9) \\ \text { No } & 455(87) & 1538(91)\end{array}$

Pancreatitis diagnosis

$\begin{array}{lll}\text { Yes } & 37(7) & 19(1) \\ \text { No } & 491(93) & 1681(99)\end{array}$

Gallstones or gallbladder

inflammation

$\begin{array}{lll}\text { Yes } & 95(18) & 207(12) \\ \text { No } & 432(82) & 1493(88)\end{array}$

Alcohol (ever had at least one alcoholic drink per month)

\begin{tabular}{lll} 
Yes & $447(84)$ & $1396(82)$ \\
No & $85(16)$ & $305(18)$ \\
\hline
\end{tabular}


Table 2 Odds Ratios (OR) and 95\% confidence intervals (CI) for pancreatic cancer (PanCA) associated with smoking status, intensity and duration, San Francisco Bay Area, California

\begin{tabular}{|c|c|c|c|c|}
\hline & & $\begin{array}{l}\operatorname{PanCA}^{\mathrm{a}} \\
\mathrm{N}=532 \\
\mathrm{n}(\%)\end{array}$ & $\begin{array}{l}\text { Controls }^{a} \\
N=1701 \\
\text { n (\%) }\end{array}$ & OR $(95 \% \mathrm{Cl})^{\mathrm{b}}$ \\
\hline & Never smoked & $163(32)$ & $650(40)$ & 1.0 (Ref.) \\
\hline \multicolumn{5}{|l|}{ Cigarette Smoking } \\
\hline & Former smoker $^{c}$ & $241(47)$ & $781(48)$ & $1.1(0.87-1.4)$ \\
\hline & Current smoker $^{d}$ & $112(22)$ & $197(12)$ & $1.9(1.4-2.7)$ \\
\hline & & & P-trend & 0.0002 \\
\hline Ever smoked cigars and/or pipes ${ }^{e}$ & & $100(19)$ & $334(32)$ & $0.88(0.66-1.2)$ \\
\hline \multicolumn{5}{|l|}{ Average cigarettes/day } \\
\hline & $<20$ & $194(38)$ & $608(37)$ & $1.2(0.92-1.5)$ \\
\hline & $20-<40$ & $137(27)$ & $329(20)$ & $1.4(1.0-1.9)$ \\
\hline & $40+$ & $22(4)$ & $41(3)$ & $1.8(0.99-3.1)$ \\
\hline & & & P-trend & 0.008 \\
\hline \multicolumn{5}{|l|}{ Years smoked } \\
\hline & $<20$ & $177(34)$ & $637(39)$ & $0.9(0.68-1.7)$ \\
\hline & $20-<40$ & $64(12)$ & $144(9)$ & $1.3(0.98-1.7)$ \\
\hline & $40+$ & $112(22)$ & $197(12)$ & $1.8(1.3-2.4)$ \\
\hline & & & P-trend & 0.0001 \\
\hline \multicolumn{5}{|l|}{ Pack years } \\
\hline & $<20$ & $129(25)$ & $487(30)$ & $1.1(0.81-1.4)$ \\
\hline & $20-<40$ & $110(21)$ & $310(19)$ & $1.2(0.90-1.6)$ \\
\hline & $40+$ & $114(22)$ & $181(11)$ & $2.0(1.5-2.8)$ \\
\hline & & & P-trend & $<.0001$ \\
\hline
\end{tabular}

a The number of participants may vary because of missing data.

${ }^{b}$ Adjusted for: age, education, race, ethnicity, diabetes, pancreatitis, gallbladder disease, alcohol intake and body mass index.

c Includes smokers who quit $\geq 1$ year prior to diagnosis/interview.

d Includes former smokers who quit within the immediate 1 year prior to interview.

e Includes cigar and pipe smokers who also smoked cigarettes and 16 cases and 73 controls who were cigar and/or pipe smokers who did not smoke cigarettes.

\section{Smoking Cessation}

The effects of smoking cessation were examined in mutually exclusive groups according to smoking duration (Table 3 ). Former smokers who quit $\geq 10$ years prior to diagnosis or interview had an OR similar to that of nonsmokers $(\mathrm{OR}=0.99,95 \% \mathrm{CI}=0.77-1.3$; data not in tables) whereas for former smokers who quit $\leq 10$ years ago the OR was $1.6(95 \% \mathrm{CI}=1.1-2.3)$. Relative to current smokers, risk diminished among former smokers who had quit $10-<15$ years prior to diagnosis or interview. Former smokers who had quit for $\geq 15$ years had no elevated risk of pancreatic cancer. We also conducted dichotomized analyses that were stratified by years since quitting to assess whether duration of cessation ( $<10$ years, $\geq 10$ years) modified the effect of lifetime or daily cigarette consumption on risk of pancreatic cancer (Table 4). Former smokers who quit ten or more years prior to diagnosis or interview had an OR similar to that of nonsmokers regardless of prior smoking intensity (Table 4). However, the effect of smoking cessation among those who quit fewer than ten years prior to diagnosis or interview varied somewhat by prior smoking intensity when compared to nonsmokers (Table 4). For example, the risk of pancreatic cancer for those who smoked for 40 or more years was similar to current smokers $(\mathrm{OR}=1.8)$, but not for those who had smoked fewer than 40 years $(\mathrm{OR}=1.3)$. However, confidence limits overlapped and tests for homogeneity showed that the estimated ORs were similar by smoking intensity or time of cessation (Table 4). 
Table 3 Odds Ratios (OR) and 95\% confidence intervals (CI) for pancreatic cancer (PanCA) associated with cigarette smoking cessation, San Francisco Bay Area, California.

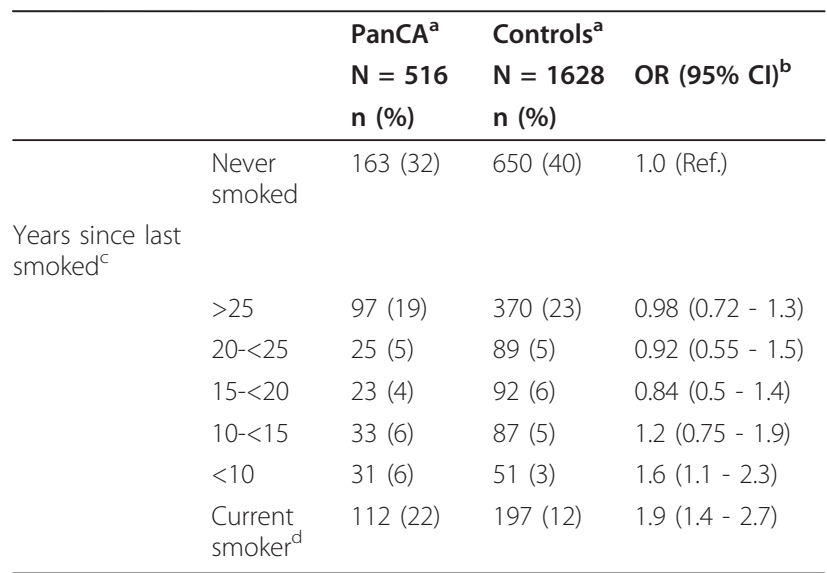

${ }^{a}$ The number of participants may vary because of missing data.

${ }^{\mathrm{b}}$ Adjusted for: age, education, race, ethnicity, diabetes, pancreatitis, gallbladder disease, alcohol intake and body mass index.

c Includes smokers who quit $\geq 1$ year prior to diagnosis/interview.

${ }^{d}$ Includes former smokers who quit within the immediate 1 year prior to interview.

Table 4 Odds Ratios (OR) and 95\% confidence intervals (CI) for pancreatic cancer (PanCA) associated with cigarette smoking cessation in relation to frequency of use compared with nonsmokers, San Francisco Bay Area, California.

\begin{tabular}{|c|c|c|}
\hline \multirow{3}{*}{$\begin{array}{l}\text { Lifetime Cigarette } \\
\text { Frequency } \\
\text { of Use }^{c}\end{array}$} & \multicolumn{2}{|c|}{ Years since quitting $^{a}$} \\
\hline & $<10$ & $>=10$ \\
\hline & OR $(95 \% \mathrm{Cl})^{\mathrm{b}}$ & OR $(95 \% \mathrm{Cl})^{\mathrm{b}}$ \\
\hline$<40$ years smoked & $1.3(0.81-2.2)$ & $1.0(0.76-1.3)$ \\
\hline$>=40$ years smoked & $1.8(1.1-2.9)$ & $0.99(0.56-1.7)$ \\
\hline $\begin{array}{l}\text { Test for Homogeneity } \\
\text { (p-value) }\end{array}$ & & 0.29 \\
\hline$<20$ cigarettes/day & $1.8(1.2-2.8)$ & $0.96(0.71-1.3)$ \\
\hline$>=20$ cigarettes/day & $1.3(0.75-2.2)$ & $1.0(0.73-1.5)$ \\
\hline $\begin{array}{l}\text { Test for Homogeneity } \\
\text { (p-value) }\end{array}$ & & 0.26 \\
\hline$<40$ packyears & $1.8(1.1-2.8)$ & $0.96(0.73-1.3)$ \\
\hline$>=40$ packyears & $1.4(0.83-2.3)$ & $1.2(0.74-1.8)$ \\
\hline $\begin{array}{l}\text { Test for Homogeneity } \\
\text { (p-value) }\end{array}$ & & 0.45 \\
\hline
\end{tabular}

${ }^{a}$ The number of participants may vary because of missing data.

b Compared with nonsmokers. Adjusted for: age, education, race, ethnicity, diabetes, pancreatitis, gallbladder disease, alcohol intake and body mass index.

c Includes smokers who quit $\geq 1$ year prior to diagnosis/interview.

d Breslow-Day test.

\section{Passive Exposure to Smoking}

Passive exposure to household and workplace smoke was not associated with an increased risk of pancreatic cancer (Table 5). Childhood household exposure (OR = $0.99)$, adult household exposure $(\mathrm{OR}=1.2)$ and workplace $(\mathrm{OR}=1.1)$ exposure were not associated with an increased risk of pancreatic cancer after adjustment for smoking behavior (never, past, current). The categories are not mutually exclusive, which allowed for the examination of exposure to multiple exposure environments (e.g. exposure at home and work). Analysis of mutually exclusive exposure environments (e.g. exposure at either home or work) did not yield significant associations with pancreatic cancer risk (data not shown).

\section{Discussion}

The results from this population-based case-control study expand upon those of earlier case-control and cohort studies that have demonstrated the association between smoking and pancreatic cancer risk. The current estimation of the overall risk of pancreatic cancer among current smokers is consistent with the 1.6- to 1.9-fold increased risk reported by other investigators [14]. Our results support previous work that has identified a relationship between smoking intensity and duration and pancreatic cancer [14,17]. After adjustment for potential confounders and suspected risk factors, we observed a two-fold increased risk of pancreatic cancer among those who smoked 40 or more pack years and similarly elevated risks were observed for those who had smoked for more than 40 years or more than 40 cigarettes per day. Unlike previous studies reporting stronger smoking-related associations among women than among men $[9,29,30]$, we observed similar risks for women and men. In contrast to a recent meta-analysis [14], we did not observe an increased risk of pancreatic cancer among current cigar and/or pipe smokers. However, limited sample size restricted our examinations to participants who ever smoked pipes and cigars and who also smoked cigarettes.

The effects of smoking cessation in our study population also were similar to previously reported results $[14,17]$. In the current study, the risk estimate among former smokers who quit 10 years prior to diagnosis or interview was similar to the decrease observed in the meta-analysis of 82 published studies [14]. To eliminate the combined effect of short and long-term duration of years since quit, we expanded upon these analyses by investigating duration of smoking cessation in mutually exclusive groups. Our results showed that former smokers who had quit fewer than 13 years prior to diagnosis or interview had a greater than 1.6 fold elevated risk of pancreatic cancer. In contrast, former smokers who had quit $10-<15$ or $\geq 15$ years prior to diagnosis or 
Table 5 Odds Ratios (OR) and 95\% confidence intervals (CI) for pancreatic cancer (PanCA) associated with passive exposure to cigarette smoke, San Francisco Bay Area, California.

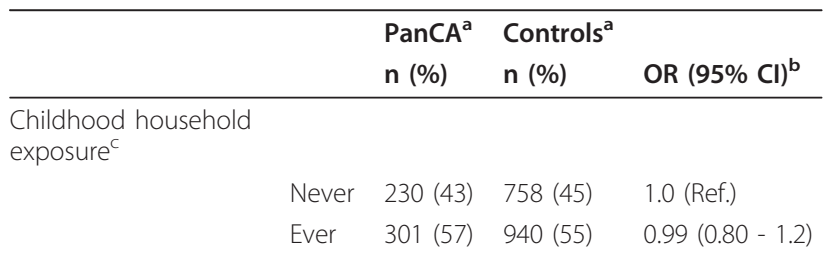

Adulthood household exposure

$\begin{array}{llll}\text { Never } & 239(45) & 888(52) & 1.0 \text { (Ref.) } \\ \text { Ever } & 293(55) & 813(48) & 1.2(0.96-1.5)\end{array}$

Adulthood workplace exposure

$$
\begin{array}{llll}
\text { Never } & 232(45) & 827(48) & 1.0(\text { Ref.) } \\
\text { Ever } & 293(55) & 874(45) & 1.1(0.86-1.3)
\end{array}
$$

${ }^{a}$ The number of participants may vary because of missing data

b Adjusted for: age, education, race, smoking status (never, former, current), ethnicity, diabetes, pancreatitis, gallbladder disease, alcohol intake and BMI adjusted

c Exposure environments are not mutually exclusive (i.e. participants could have been exposed in multiple environments)

interview had lower magnitude ORs that were not different from unity. Participants who had stopped smoking for ten or more years prior to diagnosis or interview had no increased risk of pancreatic cancer relative to nonsmokers, regardless of prior smoking intensity. In contrast, the effect of smoking cessation among those who had quit fewer than ten years prior to diagnosis or interview varied by prior smoking intensity. These results are similar to those of a previous study that examined the combined effects of smoking cessation and prior smoking intensity [31]. Relative to current smokers, a consistent reduction in risk was observed for those former smokers who had quit for fewer than 10 to at least 25 years (in 5-year mutually exclusive groups).

Environmental tobacco smoke contains thousands of chemicals including dozens of known carcinogens [32] yet a link between passive or secondhand smoke exposure and pancreatic cancer has not been established $[33,34]$. In this study, passive exposure to household and workplace cigarette smoke among adults was not associated with an increased risk of pancreatic cancer, nor was childhood household exposure. We may not have expected to see an association with childhood or early adult exposure to passive smoke due to the long time interval to cancer development. This is supported by our results that demonstrate no increased risk for personal smoking after ten years of cessation.
Strengths of this study included the large sample size, the population-based design, similarity of response rates for the cases and controls, and the low case refusal rate of 8 percent. The primary reason for lost patients was aggressive disease and the high mortality rate of pancreatic cancer. Study design methods used to diminish potential selection bias included random-digit-dial to identify age-, sex- and county-matched controls from the same population from where the cases were obtained and rapid case ascertainment to identify all incident pancreatic cancer cases diagnosed in six Bay Area counties between 1994 and 1999. Trained experienced interviewers who were unaware of the study hypotheses conducted in-person interviews with participants to diminish interviewer bias and no proxy interviews were conducted to diminish recall and misclassification bias. Several limitations also should be considered when interpreting the results of this study. In particular, as in all case-control investigations, there may have been recall bias due to differential reporting of past smoking by cases versus controls because smoking could possibly have been known as a risk factor for pancreatic cancer among some individuals. However, cases and controls were equally likely to have quit smoking, suggesting that the likelihood that the observed associations were due to recall bias among the cases was low. In addition, the eligible cases who had died prior to interview may have been smokers disproportionately to nonsmokers and this may have affected the ORs resulting in bias toward the null. Multiple comparisons were made in this study, and some results could have been due to chance. However, this study was designed to test specific hypotheses related to smoking, and the outcomes of the analyses were generally consistent with previous studies supporting a causative role of cigarette smoking for pancreatic cancer.

\section{Conclusions}

These data support evidence that cigarette smoking is a risk factor for pancreatic cancer. This investigation reinforces the results of earlier studies by demonstrating the benefits of smoking cessation on risk of pancreatic cancer and extends the earlier reports by: quantifying the relationship between cigarette smoking intensity and pancreatic cancer; estimating the modifying effects of smoking cessation by smoking duration, pack-years smoked, and cigarettes smoked per day on risk of developing pancreatic cancer; and assessing the effects of cigar and pipe smoking and passive cigarette smoke exposure on the risk of pancreatic cancer. These data along with the results from previous studies suggest that future work should focus on the effect that declining smoking rates will have on pancreatic cancer incidence. 


\section{Acknowledgements}

Support provided in part by grants CA59706, CA108370, CA109767, CA89726 (E.A. Holly, PI) from the National Cancer Institute, National Institutes of Health, by the Rombauer Pancreatic Cancer Research Fund and by the Hasbun Fund. The collection of cancer incidence data for the UCSF study was supported by the California Department of Public Health as part of the statewide cancer reporting program; the National Cancer Institute's

Surveillance, Epidemiology and End Results Program under contract N01-PC35136 to the Northern California Cancer Center; and the Centers for Disease Control and Prevention's National Program of Cancer Registries.

\section{Author details}

'California Pacific Medical Center Research Institute, CA, 94107, USA. ${ }^{2}$ Department of Epidemiology and Biostatistics, University of California San Francisco, CA, 94143, USA.

\section{Authors' contributions}

GJT conducted the data analysis; participated in data interpretation; and drafted the manuscript. EAH conceived of the study; participated in study design, coordination, and acquisition of data; participated in data interpretation; and revised the manuscript critically. FW participated in data analysis and interpretation. PMB participated in study design, coordination, and acquisition of data; participated in data analysis and interpretation; and revised the manuscript critically. All authors read and approved the final manuscript

\section{Competing interests}

The authors declare that they have no competing interests.

Received: 3 March 2010 Accepted: 15 April 2011

Published: 15 April 2011

\section{References}

1. American Cancer Society Facts and Figures 2010. Atlanta, GA: American Cancer Society; 2010.

2. Lowenfels $A B$, Maisonneuve P: Epidemiology and prevention of pancreatic cancer. Jpn J Clin Oncol 2004, 34(5):238-244.

3. Longnecker DS, Karagas MR, Tosteson TD, Mott LA: Racial differences in pancreatic cancer: comparison of survival and histologic types of pancreatic carcinoma in Asians, blacks, and whites in the United States. Pancreas 2000, 21(4):338-343.

4. Fesinmeyer MD, Austin MA, Li Cl, De Roos AJ, Bowen DJ: Differences in survival by histologic type of pancreatic cancer. Cancer Epidemiol Biomarkers Prev 2005, 14(7):1766-1773.

5. Zell JA, Rhee JM, Ziogas A, Lipkin SM, Anton-Culver H: Race, socioeconomic status, treatment, and survival time among pancreatic cancer cases in California. Cancer Epidemiol Biomarkers Prev 2007, 16(3):546-552.

6. Silverman DT, Hoover RN, Brown LM, Swanson GM, Schiffman M, Greenberg RS, Hayes RB, Lillemoe KD, Schoenberg JB, Schwartz AG, et al: Why do Black Americans have a higher risk of pancreatic cancer than White Americans? Epidemiology 2003, 14(1):45-54.

7. Gong Z, Holly EA, Bracci PM: Intake of folate, vitamins B6, B12 and methionine and risk of pancreatic cancer in a large population-based case-control study. Cancer Causes Control 2009, 20(8):1317-1325.

8. Gong Z, Holly EA, Wang F, Chan JM, Bracci PM: Intake of fatty acids and antioxidants and pancreatic cancer in a large population-based casecontrol study in the San Francisco Bay Area. Int J Cancer 2010, 127(8):1893-1904.

9. Silverman DT: Risk factors for pancreatic cancer: a case-control study based on direct interviews. Teratog Carcinog Mutagen 2001, 21(1):7-25.

10. Chan JM, Wang F, Holly EA: Whole grains and risk of pancreatic cancer in a large population-based case-control study in the San Francisco Bay Area, California. Am J Epidemiol 2007, 166(10):1174-1185.

11. Chan JM, Wang F, Holly EA: Pancreatic cancer, animal protein and dietary fat in a population-based study, San Francisco Bay Area, California. Cancer Causes Control 2007, 18(10):1153-1167.
12. Chan JM, Wang F, Holly EA: Sweets, sweetened beverages, and risk of pancreatic cancer in a large population-based case-control study. Cancer Causes Control 2009, 20(6):835-846.

13. Hassan MM, Bondy ML, Wolff RA, Abbruzzese JL, Vauthey JN, Pisters PW Evans DB, Khan R, Chou TH, Lenzi R, et al: Risk factors for pancreatic cancer: case-control study. Am J Gastroenterol 2007, 102(12):2696-2707.

14. Iodice S, Gandini S, Maisonneuve P, Lowenfels AB: Tobacco and the risk of pancreatic cancer: a review and meta-analysis. Langenbecks Arch Surg 2008, 393(4):535-545.

15. Lowenfels $A B$, Maisonneuve P: Epidemiology and risk factors for pancreatic cancer. Best Pract Res Clin Gastroenterol 2006, 20(2):197-209.

16. Hart AR, Kennedy H, Harvey I: Pancreatic cancer: a review of the evidence on causation. Clin Gastroenterol Hepatol 2008, 6(3):275-282.

17. Lynch SM, Vrieling A, Lubin JH, Kraft P, Mendelsohn JB, Hartge P, Canzian F, Steplowski E, Arslan AA, Gross M, et al: Cigarette smoking and pancreatic cancer: a pooled analysis from the pancreatic cancer cohort consortium. Am J Epidemiol 2009, 170(4):403-413.

18. Fuchs CS, Colditz GA, Stampfer MJ, Giovannucci EL, Hunter DJ, Rimm EB, Willett WC, Speizer FE: A prospective study of cigarette smoking and the risk of pancreatic cancer. Arch Intern Med 1996, 156(19):2255-2260.

19. Silverman DT, Dunn JA, Hoover RN, Schiffman M, Lillemoe KD, Schoenberg JB, Brown LM, Greenberg RS, Hayes RB, Swanson GM, et al: Cigarette smoking and pancreas cancer: a case-control study based on direct interviews. J Natl Cancer Inst 1994, 86(20):1510-1516.

20. Duell EJ, Holly EA: Reproductive and menstrual risk factors for pancreatic cancer: a population-based study of San Francisco Bay Area women. Am J Epidemiol 2005, 161(8):741-747.

21. Holly EA, Eberle CA, Bracci PM: Prior history of allergies and pancreatic cancer in the San Francisco Bay area. Am J Epidemiol 2003, 158(5):432-441.

22. Hoppin JA, Tolbert PE, Holly EA, Brock JW, Korrick SA, Altshul LM, Zhang RH Bracci PM, Burse VW, Needham LL: Pancreatic cancer and serum organochlorine levels. Cancer Epidemiol Biomarkers Prev 2000, 9(2):199-205.

23. Chan JM, Wang F, Holly EA: Vegetable and fruit intake and pancreatic cancer in a population-based case-control study in the San Francisco bay area. Cancer Epidemiol Biomarkers Prev 2005, 14(9):2093-2097.

24. Eberle CA, Bracci PM, Holly EA: Anthropometric factors and pancreatic cancer in a population-based case-control study in the San Francisco Bay area. Cancer Causes Control 2005, 16(10):1235-1244.

25. Bracci PM, Wang F, Hassan MM, Gupta S, Li D, Holly EA: Pancreatitis and pancreatic cancer in two large pooled case-control studies. Cancer Causes Control 2009, 20(9):1723-1731.

26. Gupta S, Wang F, Holly EA, Bracci PM: Risk of pancreatic cancer by alcohol dose, duration, and pattern of consumption, including binge drinking: a population-based study. Cancer Causes Control 21(7):1047-1059.

27. Li D, Tang H, Hassan MM, Holly EA, Bracci PM, Silverman DT: Diabetes and risk of pancreatic cancer: a pooled analysis of three large case-control studies. Cancer Causes Control 22(2):189-197.

28. Wang F, Gupta S, Holly EA: Diabetes mellitus and pancreatic cancer in a population-based case-control study in the San Francisco Bay Area, California. Cancer Epidemiol Biomarkers Prev 2006, 15(8):1458-1463.

29. Muscat JE, Stellman SD, Hoffmann D, Wynder EL: Smoking and pancreatic cancer in men and women. Cancer Epidemiol Biomarkers Prev 1997, 6(1):15-19.

30. Nilsen TI, Vatten LJ: A prospective study of lifestyle factors and the risk of pancreatic cancer in Nord-Trondelag, Norway. Cancer Causes Control 2000, 11(7):645-652.

31. Ji BT, Chow WH, Dai Q, McLaughlin JK, Benichou J, Hatch MC, Gao YT, Fraumeni JF Jr: Cigarette smoking and alcohol consumption and the risk of pancreatic cancer: a case-control study in Shanghai, China. Cancer Causes Control 1995, 6(4):369-376

32. Brownson RC, Figgs LW, Caisley LE: Epidemiology of environmental tobacco smoke exposure. Oncogene 2002, 21(48):7341-7348.

33. Gallicchio L, Kouzis A, Genkinger JM, Burke AE, Hoffman SC, Diener-West M, Helzlsouer KJ, Comstock GW, Alberg AJ: Active cigarette smoking, household passive smoke exposure, and the risk of developing pancreatic cancer. Prev Med 2006, 42(3):200-205. 
34. Villeneuve PJ, Johnson KC, Mao Y, Hanley AJ: Environmental tobacco smoke and the risk of pancreatic cancer: findings from a Canadian population-based case-control study. Can J Public Health 2004, 95(1):32-37.

\section{Pre-publication history}

The pre-publication history for this paper can be accessed here: http://www.biomedcentral.com/1471-2407/11/138/prepub

doi:10.1186/1471-2407-11-138

Cite this article as: Tranah et al: Cigarette, cigar and pipe smoking, passive smoke exposure, and risk of pancreatic cancer: a populationbased study in the San Francisco Bay Area. BMC Cancer 2011 11:138.

Submit your next manuscript to BioMed Central and take full advantage of:

- Convenient online submission

- Thorough peer review

- No space constraints or color figure charges

- Immediate publication on acceptance

- Inclusion in PubMed, CAS, Scopus and Google Scholar

- Research which is freely available for redistribution

Submit your manuscript at www.biomedcentral.com/submit 